\title{
Numerical Simulation for the Effect of Biodiesel Addition on the Combustion, Performance and Emissions Parameters of Single Cylinder Diesel Engine
}

\author{
Mohammed S. Edam ${ }^{a}$ and Mohamed F. Al-Dawody ${ }^{a *}$ \\ ${ }^{a}$ Department of mechanical engineering, University of Al-Qadisiyah, Al-Qadisiyah, Iraq.
}

\section{ARTICLE INFO}

\section{Article history:}

Received 07 May 2019

Received in revised form 18 June 2019

Accepted 29 June 2019

\section{Keywords:}

Castor methyl ester

Diesel engine

Diesel-rk software

Engine performance

Emission

\begin{abstract}
A B S T R AC T
This work examines the characteristics of combustion, performance and emissions of single cylinder diesel engine powered by diesel fuel and a different volume percentages of the caster methyl ester (CME). The selected biodiesel is studied numerically using the simulation program diesel-rk. The results reported that peak pressure is closer to the top dead center (TDC), as the percentage of CME. The brake specific fuel consumption (BSFC) is increased slightly as the blending of biodiesel is increased. All the selected biodiesel ratios are found to release higher NOx emission compared to diesel. Dramatic reduction in smoke levels $15.25 \%, 35.3 \%, 40.7 \%, 45.71 \%, 49.43 \%$, and $52.73 \%$ with B10\% CME, B20\% CME, B30\% CME, $\mathrm{B} 50 \% \mathrm{CME}, \mathrm{B} 70 \% \mathrm{CME}$ and $\mathrm{B} 100 \% \mathrm{CME}$ respectively. B20\% CME biodiesel was the best remarked ratio which gives slight variations in performance with a good reduction in the carbon emissions compared to diesel fuel. The results are compared with other researchers work and nice convergence is observed.
\end{abstract}

(C) 2019 University of Al-Qadisiyah. All rights reserved.

\section{Introduction}

Vegetable oil has been a competitive alternative to diesel since 1900, gaining considerable attention during the Second World War because of the lack of fuel at that time and the difficulty of obtaining it. After World War, the world turned to fossil fuel production, which was found affordable because of low production cost. However, after oil production was controlled by OPEC's, the problem of environmental pollution was greatly exacerbated and people's lives were threatened with great risks. It becomes necessary to find an alternative fuel. Access to oil from plant resources has attracted considerable attention. In many countries, vegetable oils are used after esterification as "biodiesel". Biodiesel has evolved to be one of the most widely used biofuels for the partial replacement of petroleum based diesel, especially in recent years. Vegetable oils are most commonly used for biodiesel production [1].

Biodiesel is a sustainable energy source to meet the growing global demand for transportation energy and significantly reduce greenhouse gas emissions. Non-edible vegetable oils are a highly suitable candidate for production of biodiesel where they can be grown in marginal and harsh lands requiring less soil fertility, less maintenance and less water than arable land for edible plant oils [2]. Bio-fuels, particularly castor oil and castor methyl ester, might help a lot to meet the future energy supply demands as well as contributing to the reduction of greenhouse gases emissions and other harmful products of the combustion process[3].

\footnotetext{
* Corresponding author.

E-mail address: Mohamed.AlDawody@qu.edu.iq (Mohamed F. Al-Dawody)
} 


\begin{tabular}{|c|c|c|c|}
\hline \multicolumn{4}{|c|}{ Nomenclature } \\
\hline$A_{o}, A_{2}, A_{3}$ & Constants. & $P M$ & Particulate Matter \\
\hline B10 & Volume blend contains $90 \%$ diesel plus $10 \% \mathrm{CME}$ & $R$ & Constant of gas (universal) \\
\hline$B 20$ & Volume blend contains $80 \%$ diesel plus $20 \% \mathrm{CME}$ & $C M E$ & Castor Methyl Ester \\
\hline$B 30$ & Volume blend contains $70 \%$ diesel plus $30 \% \mathrm{CME}$ & rpm & revolutions / minute \\
\hline$B 50$ & Volume blend contains $50 \%$ diesel plus $50 \% \mathrm{CME}$ & rps & revolutions /second \\
\hline$B 70$ & Volume blend contains $30 \%$ diesel plus $70 \% \mathrm{CME}$ & $T$ & temperature in the cylinder \\
\hline$B 100$ & Volume blend contains $100 \%$ CME & $t$ & time \\
\hline$B S F C$ & Brake Specific Fuel Consumption (kg/kW.h) & $T D C$ & Top Dead Centre \\
\hline$D F$ & Diesel Fuel & $U$ & Instantaneous fuel velocity \\
\hline$B S N$ & Bosch Smoke Number & $U_{0}$ & Spray Initial velocity \\
\hline$[C]$ & cylinder concentration soot & $U_{m}$ & The velocity of the spray's front \\
\hline${ }^{o} \mathrm{C}$ & degrees centigrade & $V$ & The cylindrical volume \\
\hline${ }^{\circ} \mathrm{CA}$ & crank angle degrees & $x$ & heat release proportion \\
\hline$C N$ & Cetane Number of fuel & $x_{o}$ & The fraction of the fuel vapour forming in the delay period. \\
\hline$E_{a}$ & the apparent activation energy for the auto ignition process & & \\
\hline$K_{T}$ & Constant of Evaporation & \multicolumn{2}{|c|}{ Greek symbols } \\
\hline$l$ & spray length & $\sigma$ & cylinder fuel fractions \\
\hline $\operatorname{lm}$ & Penetration distance & $\sigma_{\mathrm{u}}$ & Vapor fraction \\
\hline$m_{f}$ & Fuel mass & $\tau$ & Delay period (second) \\
\hline NOx & Nitrogen Oxides & $\theta$ & Crank angles (degree) \\
\hline$p$ & cylinder pressure (pa) & $\phi$ & Equivalence ratio \\
\hline$p_{s}$ & fuel saturation vapour pressure & $\gamma$ & Exhaust gas exponent \\
\hline
\end{tabular}

One of the most attractive features of biodiesel is its biodegradability and being more environmentally friendly than fossil fuels, resulting in less environmental impact when it releases harmful emissions. Where emissions such as total hydrocarbons and carbon monoxide were observed to be significantly lower with biodiesel than diesel fuel [1]. In addition, it contains about $10-15 \%$ oxygen by weight [2].

After the production of biofuels in the world has grown widely, some criteria have to be put in place to ensure the quality of production, including the specifications of the American standard of testing Materials (ASTM) and European Union (EU) specifications. Hence, researchers began to research the possibility of using biodiesel in diesel engines [3]. The researchers have been also using biodiesel as a renewable source to investigate the characteristics of emission, performance as well as combustion parameters. Lin et al. [4], studied diesel oil and 8 kinds of biodiesel in CI engine. Experimental results showed, an increase in BSFC, decreased engine performance slightly and decreased smoke emissions, which is due to the uniform mixing of air and fuel and the strengthening of oxygen due to using a vegetable oil methyl ester. The nitrogen oxides emission is increased as the temperature of combustion is increased total hydrocarbon emission (THC) are decreased because of many factors such as uniform mixing of Fuel-air, higher oxygen quantity and due to longer spray penetrations as well. R. Sattanathan [5] investigated the production of biodiesel (Castor Methyl Ester) (CME)) from castor oil with its performance and emission testing, and the study focused on testing the engine using a mixture of CME. The fuel mixture B25, B50, B75, and B100 is prepared and fed in the 4 strokes, one cylinder, direct injection engine, water cooled with a compression ratio of 17.5: 1. Results of author's experiments indicate, the brake power of CME was almost similar for the diesel engine, while the specified fuel consumption was higher than diesel. Also, the emission of hydrocarbons and smoke for CME is less than diesel emissions.

S. Lee et al. [6] studied the effects of the Karanja oil methyl ester (KOME) blending ratio on spray properties, engine performance analysis and exhaust emissions from the Karanja biodiesel mix. In the engine experience, lower torque, brake thermal efficiency (BTE) and exhaust gas temperature were observed, as well as higher fuel consumption for the biodiesel mix compared to diesel because of the lower heating value of the Karanja biodiesel.

The research work is aimed to study the use of various CME biodiesel blending ratios on combustion, and parameters of emissions and performance of single cylinder diesel engine using Diesel-rk simulation program.

\section{Biodiesel properties}

The physical properties of the prepared biodiesel along with diesel fuel are measured accurately at ALDORA refinery factor according to the table reported below. Table 1. displays the characteristics of a different mix of DF and CME biodiesel. The numerical analysis was performed on a direct injection diesel engine and water cooled using a single cylinder. The engine specifications are displayed in Table 2.

Table (1). Diesel and CME blends properties

\begin{tabular}{llllll}
\hline Property & $\begin{array}{l}\text { Density } \\
\text { at } \mathbf{1 5}^{\mathbf{}} \mathbf{C} \\
\left(\mathbf{k g} / \mathbf{m}^{\mathbf{3}}\right)\end{array}$ & $\begin{array}{l}\text { Viscosity } \\
\text { at } \mathbf{4 0}^{\circ} \mathbf{C} \\
(\mathbf{p a . s})\end{array}$ & $\begin{array}{l}\text { Calorific } \\
\text { value } \\
(\mathbf{M J} / \mathbf{k g})\end{array}$ & $\begin{array}{l}\text { Surface } \\
\text { tension } \\
(\mathbf{N} / \mathbf{m})\end{array}$ & $\begin{array}{l}\text { Cetane } \\
\text { number }\end{array}$ \\
\hline Diesel & 830 & 0.002241 & 45.836 & 0.028 & 53.4 \\
$\mathbf{B 1 0 \%}$ CME & 837 & 0.003068 & 45.686 & 0.02953 & 53.06 \\
$\mathbf{B 2 0 \%} \mathbf{C M E}$ & 845.2 & 0.003925 & 45.556 & 0.03106 & 52.9 \\
$\mathbf{B 3 0 \%} \mathbf{C M E}$ & 851 & 0.004724 & 45.386 & 0.03259 & 52.38 \\
$\mathbf{B 5 0 \%} \mathbf{C M E}$ & 865 & 0.00638 & 45.086 & 0.03565 & 51.7 \\
$\mathbf{B 7 0 \%} \mathbf{C M E}$ & 879 & 0.008036 & 44.786 & 0.03871 & 51.02 \\
$\mathbf{C M E}$ & 900 & 0.01052 & 44.336 & 0.0433 & 50 \\
\hline
\end{tabular}

Table (2) Engine Dimensions[7]

\begin{tabular}{ll}
\hline Engine Brand & Kirloskar TAF-1 \\
\hline Type of engine & $4-$ Stroke, Diesel Engine, single cylinder \\
Bore & $80 \mathrm{~mm}$ \\
stroke & $110 \mathrm{~mm}$ \\
The cylinder capacity & $0.553 \mathrm{~L}$ \\
The compression ratio & 15.5 \\
Rated power & $3.7 \mathrm{~kW}, 1500 \mathrm{rpm}$ \\
Orifice diameter & $0.15 \mathrm{~mm}$ \\
Injection pressure & $220 \mathrm{bar}$ \\
\hline
\end{tabular}




\section{Numerical simulation approach}

The multizone combustion model has been used in this work. The fuel distribution is sprayed with 2 stages: free jet $\&$ wall jet as illustrated in Fig. 1. There are a specific condition of evaporation and combustion for each zone identified in the model.

1. Free wall (before impingement)

- The conical nucleus of free spray.

- Front dense spray free.

- The diluted outer shell of the spray.

2. After wall impingement another 4 zones are formed:

- The near-wall flow (NWF) nucleus

- The NWF is dense on the surface of the piston.

- Front dense of the NWF.

- NWF extensible out zone.

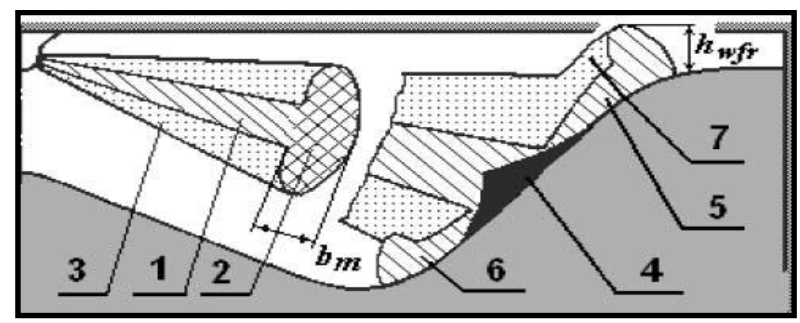

Figure 1. Diesel spray zones (M. F. Al-Dawody, [8])

The current speed and location of the elementary fuel mass (EFM) from the injector to the tip of the spray is given by to [9]:

$$
\left[U / U_{\circ}\right]^{\wedge}(3 / 2)=1-l / l_{m}
$$

Fig. 2. presents the variation of spray evolution parameters as functions of time. The Governing evaporating details are described in [8].

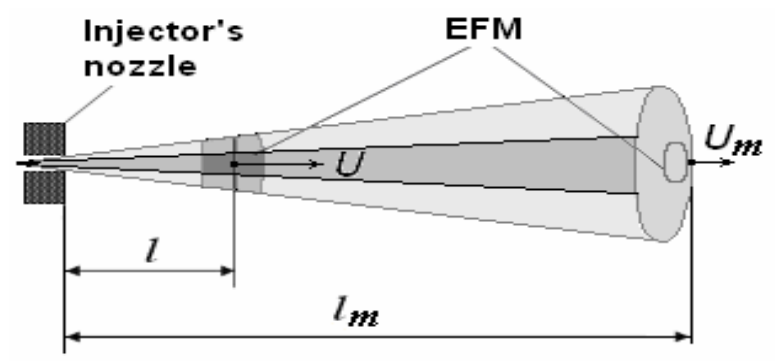

Figure 2. Spray development v/s time [8].

\subsection{Heat release model}

The fuel combustion is normally divided into four phases, which have separate chemical and physical properties that restricted combustion speed.

\section{a. Delay period.}

The period of delay is estimated from the equation of Tolstov [10]: $\tau=3.8 * \measuredangle 10 \nabla^{\wedge}(-6) \cdot n \sqrt{ }(T / P) \cdot \exp \left(E_{a} / 8.312 T-\right.$ $70 /(C N+25))$

b. The phase of uncontrolled combustion (Premixed) [11] $d x / d \tau=\varphi \circ\left[A_{\circ}\left(m_{f} / V_{i}\right)\left(\sigma_{u d}-x_{\circ}\right)\left(0.1 \sigma_{u d}+x_{\circ}\right)\right]$

$$
+\varphi_{1}\left(d \sigma_{u} / d \tau\right)
$$

c- Diffusion phase.[11]

$d x / d t=\varphi_{1}\left(d \sigma_{u} / d \tau\right)+\varphi_{2}\left(A_{2}\left(m_{f} / V\right)\left(\sigma_{u}-x\right)(\varnothing-x)\right.$

d- Combustion tail [12]

$d x / d \tau=\varphi_{3} A_{3} K_{T}(1-x)\left(\varepsilon_{b} \emptyset-x\right)$

During the process of simulations, Woschni' s formula has used to predict coefficients of heat transfer in the cylinder[13].

\subsection{The nitrogen oxides model}

The nitrogen oxide reaction is[12]:

$\mathrm{N}+\mathrm{O}_{2} \leftrightarrow \mathrm{NO}+\mathrm{O}$

$\mathrm{T}$ The reaction is depended on the oxygen concentration. The volumetric of NO concentration is given by:

$$
\frac{d[N O]}{d \theta}=\frac{2.33 * 10^{7} p \cdot e^{-\frac{38020}{T_{Z}}}\left[N_{2}\right]_{e}[O]_{e}\left(1-\left([N O] /[N O]_{e}\right)^{2}\right)}{R T_{Z}\left(1+\left(2365 / T_{Z}\right) \cdot e^{\frac{3365}{T_{Z}}} \cdot[N O] /\left[O_{2}\right]_{e}\right)} \cdot\left(\frac{1}{r p s}\right)
$$

\subsection{The soot concentration model}

Soot particle forms grow and oxidizes due to chemical reaction occurring through combustion. It has a deep impact on the pollution of the environment the concentration of soot particle is calculated[8]:

$$
[C]=\int_{\theta_{B}}^{480} \frac{d[C]}{d \tau} \frac{d \theta}{6 n}\left[\frac{0.1}{P}\right]^{\gamma}
$$

The Bosch smoke number (BSN) was obtained from Hartidge smoke equation given below[14]:

Hartidge $=100\left[1-0.9545 * e^{(-24226[C])}\right]$

The PM emissions (are obtained from[14]:

$$
[P M]=565\left[\ln \frac{10}{10-\text { Bosch }}\right]^{1.206}
$$

\subsection{Basic equations of performance[15].:}

a. Brake thermal efficiency (BTE)

Using equation (11) to calculate the brake thermal efficiency

$$
\mathrm{BTE}=\mathrm{BP} / \dot{\mathrm{m}}_{\mathrm{f}} * \mathrm{LCV}
$$

where:

LCV- Lower heating value of blended fuel $(\mathrm{kJ} / \mathrm{kg})$

b. Brake specific fuel consumption

The Brake Specific Fuel Consumption (BSFC) is calculated by using the equation (12).

$\mathrm{BSFC}=\left(\dot{\mathrm{m}}_{\mathrm{f}} / \mathrm{BP}\right) * 3600$

where: $\dot{\mathrm{m}}_{\mathrm{f}}=$ Fuel consumption rate

\section{Results and Discussion}

The range of operating conditions were constant engine speed 1500 rpm, injection pressure 220 bars and $20^{\circ}$ BTDC injection timing. The condition of full load is selected as it gives maximum smoke as well as minimum air/fuel ratio. This gives the right situations to confirm any differences among the fuel blends under study. 


\subsection{Combustion parameters}

Fig.3 presents the variation of pressure verse crank shaft angle for $\mathrm{DF}$ and biodiesel blends at full load. It is found that $\mathrm{P}_{\max }$ is 73.4436 bars for DF at 369 crank angle while it comes nearer to TDC for B100 CME where the maximum pressure was 80.2889 bars at $366^{\circ}$ crank angle. The pressure of $10 \%$ and $20 \% \mathrm{CME}$ are noticed closer to that of DF



Figure 3. Variation of cylinder pressure with crank angle

The predicted zonal temperature is described in Fig. 4. The higher combustion temperatures for CME mixtures are reported. The high flame temperature is an indicator of the high NOx emissions. The maximum temperature difference between $20 \% \mathrm{CME}$ and DF is 49 $\mathrm{K}$ at $362^{\circ}$ crank angle. It's the direct cause of the high NOx emission of biodiesel. The same observations were noted in the results of [16].

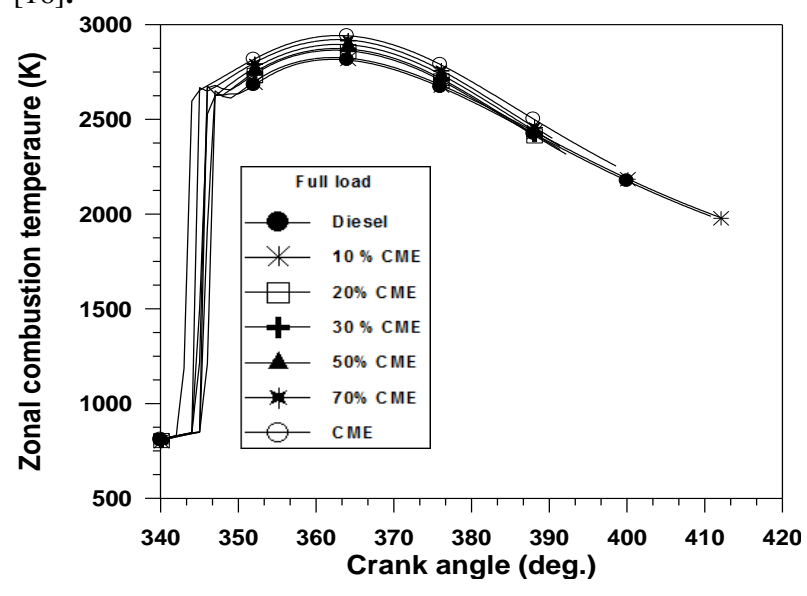

Figure 4. Variation of zonal temperature with crank angle

Figs. 5 and 6 present the computed heat release rate and the fraction of heat release for DF and CME biodiesel respectively. The heat release fraction can be defined as the ratio of heat release rate to the lower heat value of the fuel. All CME blends have an earlier start of combustion but lower combustion rates. In the diffusion phase, most fuel has been vaporizing and burning as well, because of the rapid combustion of CME biodiesel.

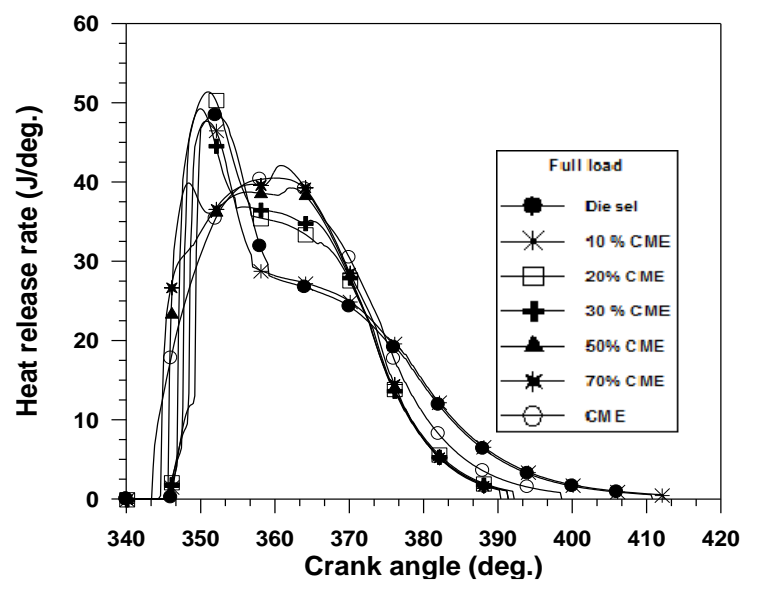

Figure 5. Show the heat release rate vs. crank angle.

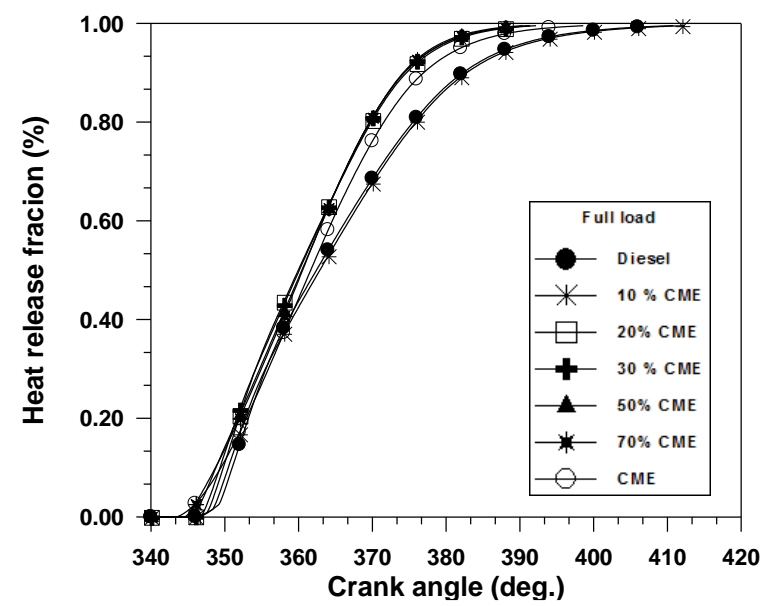

Figure 6. Show the heat release fraction vs. crank angle

Fig. 7. shows the effect of CME ratio on the delay period. Fuel ignition quality is affected by auto ignition. The shorter delay period comes as a result of the difference in cetane number the combustion starts too early, and reduction in the heat released is expected. The same findings are confirmed by [17].

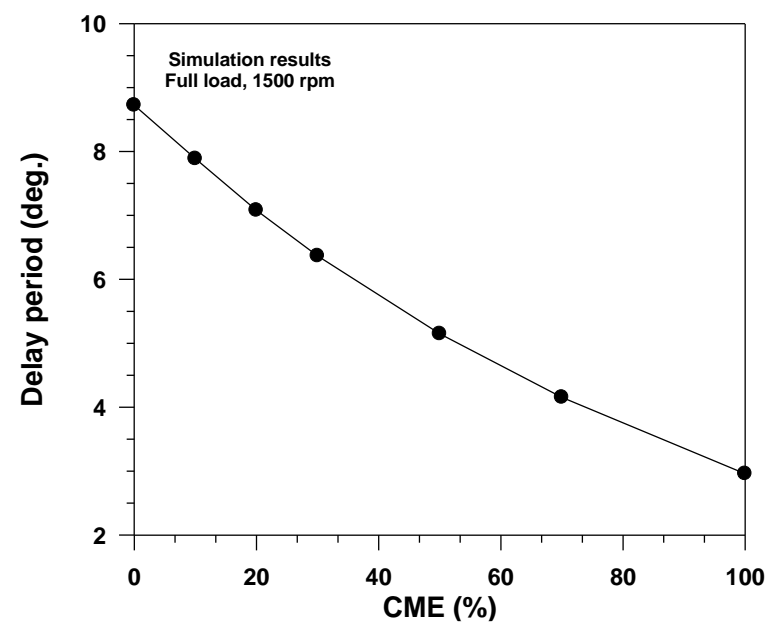

Figure 7. Effect of CME blending on ignition delay 


\subsection{Performance parameters}

Fig. 8 shows the effect of CME blending on BSFC. BSFC was found to increase with the increase in CME ratio in fuel. To obtain the same torque and output power for each tested fuel, BSFC was higher for CME and its mixtures. BSFC for the B20\%CME is higher than the DF by $4.85 \%$, while it is $7.39 \%$ higher for the CME B100. The higher level of density and lower heating energy are responsible for the increase in BSFC. These results are similar to those of [18] and [19].



Figure 8. The variation of BSFC with CME biodiesel blends

Fig. 9. shows BTE variation with CME ratios. It was observed that the BTE of the CME mixtures were less than the DF. The efficiency is slightly reduced as a result of increasing CME percentages because of lower calorific value of biofuel over that of ordinary diesel fuel.

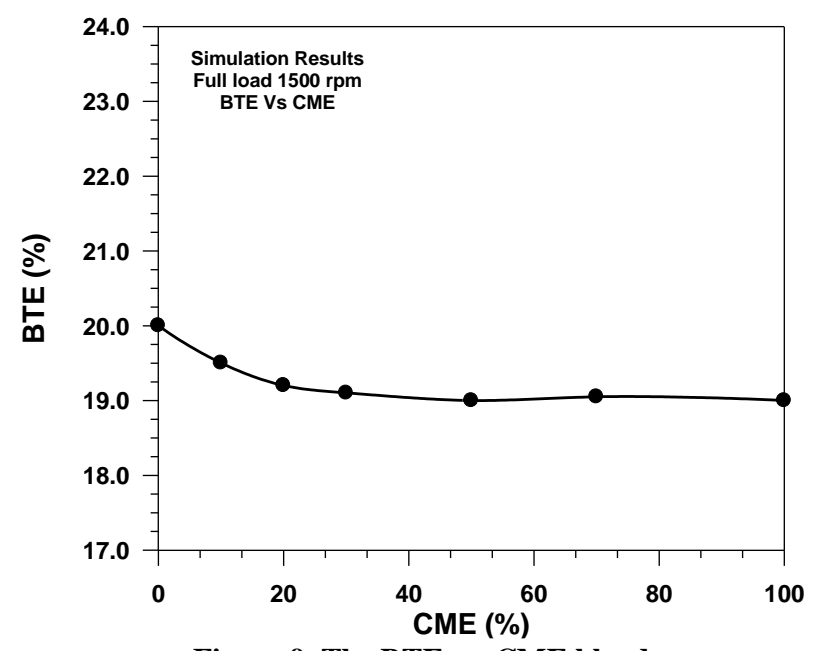

Figure 9. The BTE vs. CME blends.

\subsection{Emission parameters}

Fig. 10. describes the effect of CME blends on the smoke quantity (BSN). The smoke level for all CME blends is lower than that of the DF. The numerical findings reported a promising reduction in soot emissions by
$15.25 \%, 35.3 \%, 40.7 \%, 45.6 \%, 49.43 \%$ and $52.7 \%$ for B10, B20, B30, $\mathrm{B} 50, \mathrm{~B} 70$ and $\mathrm{B} 100$ respectively. This due to a higher quantity of oxygen exist in biodiesel which has deep impact on oxidation of fuel, hence the tendency to produce smoke is greatly reduced [20].



Figure 10. The BSN vs. CME blends

Fig. 11. explains the relation between the $\mathrm{NO}_{\mathrm{x}}$ emissions with different percentages of CME blend. The emission of $\mathrm{NO}_{\mathrm{x}}$ is higher for all $\mathrm{CME}$ blends as compared to diesel fuel. This is because of higher oxygen quantity in the biofuel. The higher cylinder pressure, as well as combustion temperature caused by early start of combustion, are the main reasons for increasing $\mathrm{NO}_{\mathrm{x}}$ emission.

The message in Fig. 10 as well as Fig. 11. says that B20\% CME was the best compromise blending ratio, where $20 \%$ gives a good reduction in BSN but a sharp increase in NOx emissions is reported hence the B20\% CME is the best promising ratio chosen in this study.

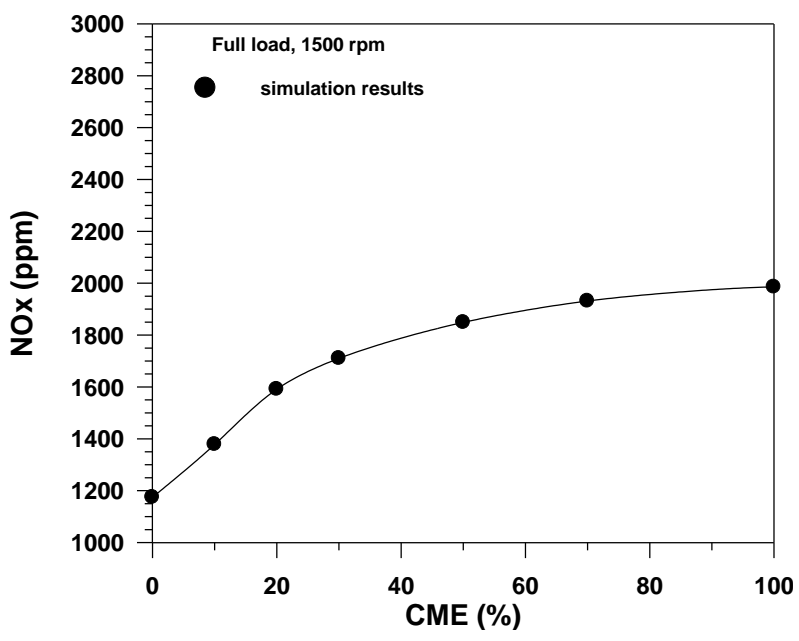

Figure 11. The relation between NOx emissions with CME biodiesel blends.

\section{Results Verification}

In this section, the point of discussion is to compare some of the results obtained from an experimental investigation of other researchers[17, 21, 22] at the same conditions of the present study with the numerical results 
of Diesel-rk software. From Figs. 12 and 13 a slight difference between the two is recorded which indicate accepted reasonable accuracy of the present work.

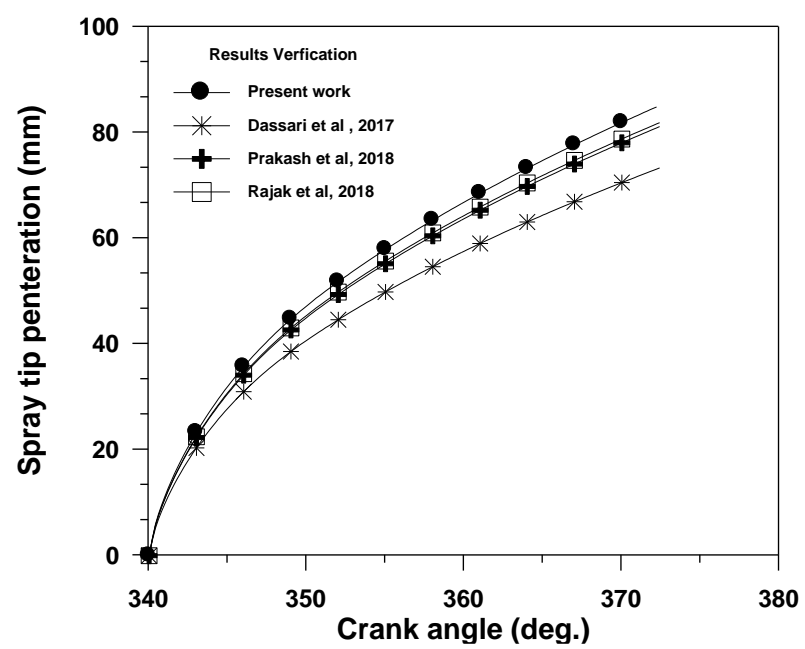

Figure 12. Verification of the spray tip penetration between different researchers.

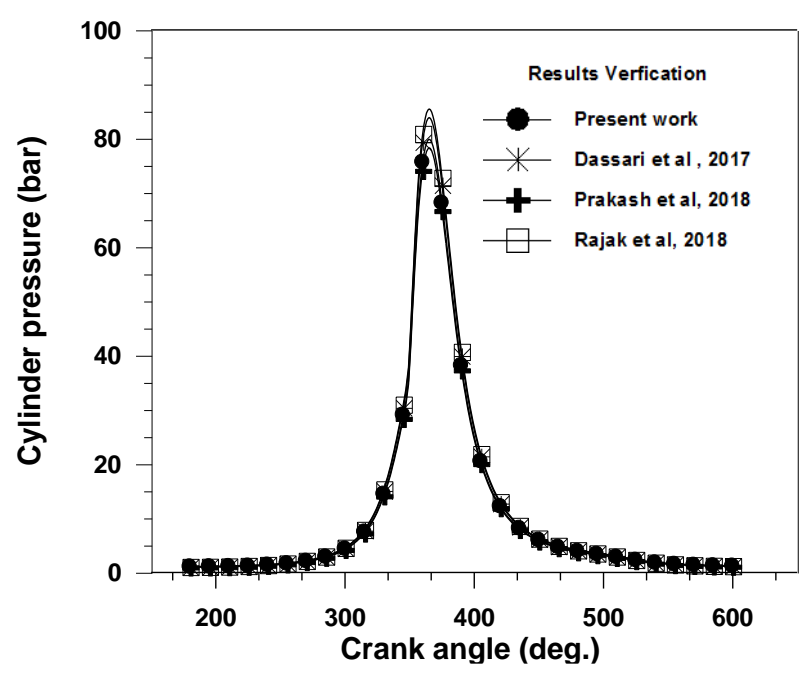

Figure 13. Verification of the cylinder pressure between different researchers

\section{Conclusions}

- CME blends are found to shift maximum pressure closer to the TDC.

- The substitution of CME blending make an early combustion atarting as compared with DF due to the shorter delay period.

- The CME ratio was observed to increase BSFC as well as decrease brake thermal efficiency slightly.

- Promising reduction in BSN with all CME mixtures as compared to DF.

- It was observed that all CME mixtures emit higher NOx emissions compared to DF.

- Best mixing percentage is $20 \%$ CME that reports lower emissions compared to pure diesel and promising results of performance is noticed as well.

\section{REFERENCES}

[1] M. Siddiqur Rahman, M. Hossain, M. Nawsher Ali Moral, Production of Biodiesel Fuels from Castor Oil Using H2SO4 as Catalyst, 2016.

[2] M.F. Al_Dawody, S. Bhatti, Experimental and computational investigations for combustion, performance and emission parameters of a diesel engine fueled with soybean biodiesel-diesel blends, Energy Procedia, 52 (2014) 421-430.

[3] G. Knothe, J. Krahl, J. Van Gerpen, The biodiesel handbook, Elsevier, 2015.

[4] B.-F. Lin, J.-H. Huang, D.-Y. Huang, Experimental study of the effects of vegetable oil methyl ester on DI diesel engine performance characteristics and pollutant emissions, Fuel, 88(9) (2009) 1779-1785.

[5] R. Sattanathan, Production of biodiesel from castor oil with its performance and emission test, Int J Sci Res, 4(1) (2015) 273-279.

[6] S. Lee, C.S. Lee, S. Park, J.G. Gupta, R.K. Maurya, A.K. Agarwal, Spray characteristics, engine performance and emissions analysis for Karanja biodiesel and its blends, Energy, 119 (2017) 138-151.

[7] M.F. Al-Dawody, A.A. Jazie, H. Abdulkadhim Abbas, Experimental and simulation study for the effect of waste cooking oil methyl ester blended with diesel fuel on the performance and emissions of diesel engine, Alexandria Engineering Journal, 58(1) (2019) 9-17.

[8] M.F. Al-Dawody, Theoretical Study for The Influence of Biodiesel Addition on The Combustion, Performance and Emissions Parameters of Single Cylinder Diesel Engine, Journal of University of Babylon, 25(5) (2017) 1830-1839.

[9] A. Kuleshov, Model for predicting air-fuel mixing, combustion and emissions in DI diesel engines over whole operating range, 0148-7191, SAE Technical Paper, 2005.

[10] A. Kuleshov, Use of multi-zone DI diesel spray combustion model for simulation and optimization of performance and emissions of engines with multiple injection, 0148-7191, SAE Technical Paper, 2006.

[11] M.F. Al-Dawody, S. Bhatti, Optimization strategies to reduce the biodiesel NOx effect in diesel engine with experimental verification, Energy conversion and management, 68 (2013) 96-104.

[12] A. Kuleshov, Multi-zone DI diesel spray combustion model and its application for matching the injector design with piston bowl shape, 0148-7191, SAE Technical Paper, 2007.

[13] G. Woschni, A universally applicable equation for the instantaneous heat transfer coefficient in the internal combustion engine, SAE transactions, (1968) 30653083.

[14] A.C. Alkidas, Relationships between smoke measurements and particulate measurements, 0148-7191, SAE Technical Paper, 1984

[15] A. Datta, B.K. Mandal, Engine performance, combustion and emission characteristics of a compression ignition engine operating on different biodieselalcohol blends, Energy, 125 (2017) 470-483.

[16] W. Yuan, A. C. Hansen, Z. Tan, Modeling of NOx Emissions of Biodiesel Fuels, in, ASAE, St. Joseph, MI, 2005.

[17] U. Rajak, P. Nashine, T.S. Singh, T.N. Verma, Numerical investigation of performance, combustion and emission characteristics of various biofuels, Energy Conversion and Management, 156 (2018) 235-252.

[18] L. Wei, R. Cheng, H. Mao, P. Geng, Y. Zhang, K. You, Combustion process and NOx emissions of a marine auxiliary diesel engine fuelled with waste cooking oil biodiesel blends, Energy, 144 (2018) 73-80.

[19] R.S. Kumbar, P.S. Patil, O. Hebbal, EXPERIMENTAL INVESTIGATION OF PERFORMANCE AND COMBUSTION CHARACTERISTICS ON A SINGLE CYLINDER LHR ENGINE USING DIESEL AND CASTOR BIODIESEL, IJRET: International Journal of Research in Engineering and Technology eISSN, 
2319-1163.

[20] H. Chen, J. He, H. Hua, Investigation on Combustion and Emission Performance of a Common Rail Diesel Engine Fueled with Diesel/Biodiesel/Polyoxymethylene Dimethyl Ethers Blends, Energy \& Fuels, 31(11) (2017) 11710-11722.

[21] T. Prakash, V.E. Geo, L.J. Martin, B. Nagalingam, Effect of ternary blends of bio-ethanol, diesel and castor oil on performance, emission and combustion in a CI engine, Renewable Energy, 122 (2018) 301-309.

[22] S.R. Dasari, A.J. Chaudhary, V.V. Goud, N. Sahoo, V. Kulkarni, In-situ alkaline transesterification of castor seeds: Optimization and engine performance, combustion and emission characteristics of blends, Energy conversion and management, 142 (2017) 200-214. 